\title{
Quality of the Treatment Goals
}

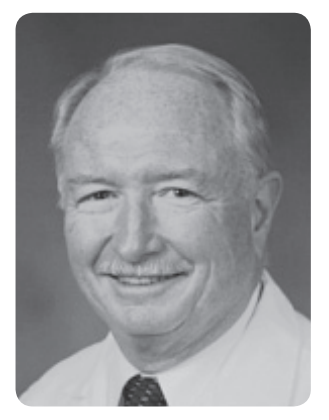

Joseph E. Van Sickels

Department of Oral and Maxillofacial Surgery,

College of Dentistry, Chandler Medical Center,

University of Kentucky

Studies of patients presenting for orthognathic surgery have shown that they have multiple functional and esthetic issues and that these vary from person to the other. Depending on the severity and type of malocclusion that the patient has, they will have functional impairments in speech, mastication, temporomandibular joint and in some instances airway function. Some of their impairments are obvious to them, others are not. Additionally they have concerns over how they appear. Incumbent upon the clinician is that we recognize how the individual differs from the average person in all planes in space given their genetic and ethnic background. As a part of the examination a discussion should include all functional and esthetic issues that a patient has as they can impact on our treatment plan. The severity of the individual variances and their concerns will determine whether a specific problem needs to be addressed. Treatment planning should be driven less by numbers derived from a cephalometric standard and more on achieving the goals of the patient. 


\section{Bio Sketch}

Dr. Joseph E. Van Sickels graduated from Dental School at the Medical College of Virginia. Following a two years General Practice Residency he finishing Oral and Maxillofacial Surgery training in 1978. He spent 17 years at the University of Texas in San Antonio before moving to Kentucky as Professor and Director of Residency Education. Dr. Van Sickels is Board Certified by the American Board of Oral Maxillofacial Surgery and has been active on the examination committee for the American Board for several years. He is on the Editorial Board of "Oral Surgery, Oral Medicine, Oral Pathology" and a reviewer for multiple journals. He is a member of the American Association of Oral and Maxillofacial Surgeons, International Association of Dental Research, and the American Cleft Palate- Craniofacial Association. He has over 130 publications in referred journals and textbooks. In addition he has given multiple presentations both nationally and internationally on trauma, orthognathic surgery and distraction. 